\title{
Dynamics of railway bridges, analysis and verification by field tests
}

\author{
Andreas Andersson ${ }^{1,2, a}$, Raid Karoumi ${ }^{1}$ \\ ${ }^{1}$ Royal Institute of Technology, Division of Structural Engineering and Bridges, Stockholm, Sweden \\ ${ }^{2}$ The Swedish Transport Administration (Trafikverket), Sweden
}

\begin{abstract}
The following paper discusses different aspects of railway bridge dynamics, comprising analysis, modelling procedures and experimental testing. The importance of realistic models is discussed, especially regarding boundary conditions, load distribution and soil-structure interaction. Two theoretical case studies are presented, involving both deterministic and probabilistic assessment of a large number of railway bridges using simplified and computationally efficient models. A total of four experimental case studies are also introduced, illustrating different aspects and phenomena in bridge dynamics. The excitation consists of both ambient vibrations, train induced vibrations, free vibrations after train passages and controlled forced excitation.
\end{abstract}

\section{Introduction}

\subsection{Future railway network in Europe}

There is an increased demand on the railway sector and much resource is spent on increasing the capacity of the existing network as well as expanding and connecting new lines. The European Commissions is working towards the creation of a Single European Railway Area and has promoted a modal shift from road to rail to achieve more competitive and resource-efficient transport system [1]. The European Commission White Paper [2] outlines the following targets:

- $30 \%$ of the road freight over $300 \mathrm{~km}$ should shift to other modes such as rail or waterborne transport by 2030 and to more than $50 \%$ by 2050 .

- Aim to triple the length of the existing high-speed railway (HSR) network by 2030 and complete a European HSR rail network by 2050 . By 2050, the majority of medium distance passenger transport should go by rail.

- By 2050, connect all core network airports to the rail network, preferably by HSR and ensure that all core seaports are sufficiently connected to the rail freight.

Hence, a considerable investment will be needed to expand and upgrade the capacity of the rail network infrastructure. To realise these ambitious goals, much effort must be spent on finding viable solutions. This includes:
- Finding methods to prove that a larger share of the existing infrastructure can be upgraded to future demands with sufficient safety margins.

- Finding more cost- and time efficient methods in building new railway infrastructure.

- Finding optimal solutions considering investment, whole life cycle cost and environmental impact.

A substantial share of the infrastructure consists of railway bridges. There are more than 300,000 railway bridges in Europe and a survey covering more than 220,000 of these [3] showed that more than $35 \%$ of the bridges are older than 100 years and only $11 \%$ are newer than 10 years. Further, $62 \%$ of the bridges have a span less than $10 \mathrm{~m}$ and only $5 \%$ are longer than $40 \mathrm{~m}$. Among the top 10 priority research areas, better assessment tools and verification of dynamic amplification factors were mentioned.

\subsection{The Swedish National Plan}

Since most of the case studies presented in this paper are based on Swedish experience, a short overview of the Swedish National Plan is given. Although Sweden is a relatively small country with less than 10 million citizens, substantial investments are made on infrastructure, with a large share in the railway sector.

The Bothnian Corridor is a freight route in progress on the North-East coast, connecting domestic transports with Norway and Finland. It is part of the European TEN-T infrastructure. Currently, the following parts have been completed:

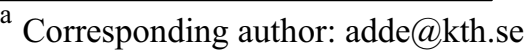


- The Bothnia Line, $190 \mathrm{~km}$ single track railway with freight capacity of 25 ton/axle (33 ton/axle on bridges) and passenger trains with allowable speed of $250 \mathrm{~km} / \mathrm{h}$.

- The Haparanda Line, $160 \mathrm{~km}$ single track railway, freight capacity of 25 ton/axle but no high-speed.

Another important freight route is the Iron ore line, $470 \mathrm{~km}$ between Luleå and Narvik in North of Sweden and Norway. It carries about $44 \%$ of the total freight transport in Sweden. It was first built in the 1880ies and has been the subject of several upgrades, first to 25 ton/axle in the 1960ies and then 30 ton/axle in the 1990ies. The line is currently under investigation for a further upgrade to 32.5 ton/axle. Although some of the infrastructure has been replaced over the years, much of the upgrade has been possible by refined assessments. Similar methodologies are adopted when upgrading other mixed traffic routes from 22.5 ton/axle, which is the governing standard in most of Sweden, to future standards of 25 ton/axle.

Dedicated HSR lines have been discussed for more than a decade and have in recent years found governmental approval. The main aim is to connect the main cities Stockholm and Gothenburg and in the extent further down to Malmö over to Denmark and Germany, see Figure 1. Detailed planning is currently in progress for the East Link Project, $155 \mathrm{~km}$ double track from South of Stockholm to Linköping. A parallel project from Gothenburg to Borås, a distance of $60 \mathrm{~km}$, is also in progress.

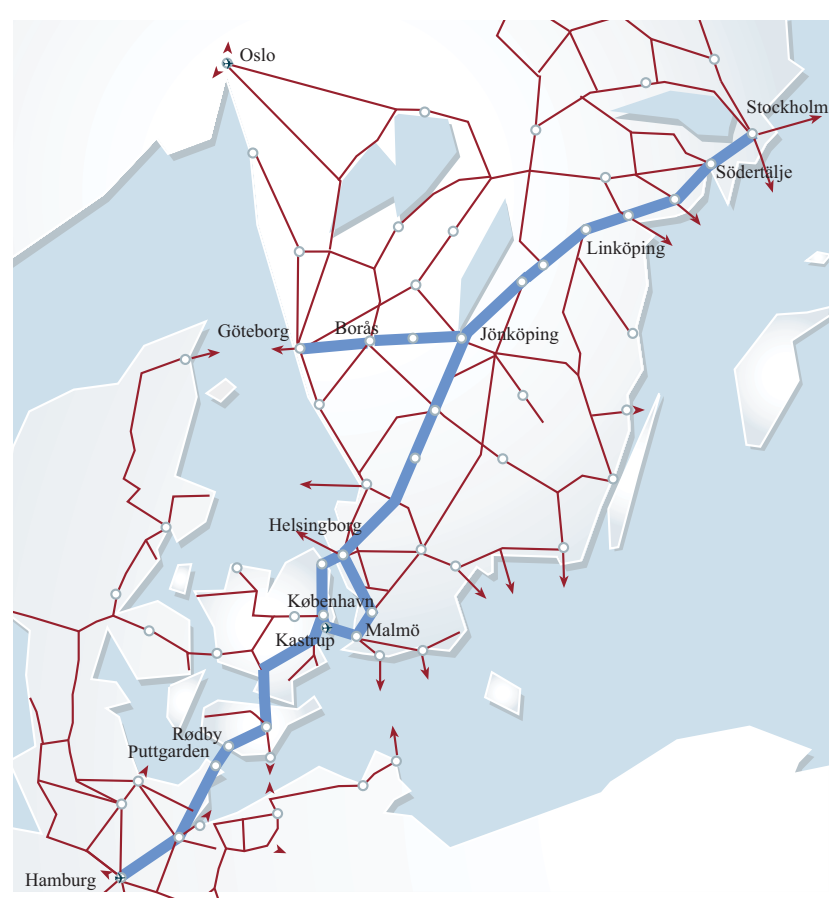

Figure 1. Plans for high-speed railway network in Sweden, reproduced from [4].

\subsection{Research within railway bridge dynamics}

To meet the demands from both the European Commission and the Swedish National Plan, extensive research is needed. Within the field of railway bridge dynamics, the know-how from other countries with experience of HSR need to be combined with the Swedish experience and local conditions. Some of the major research topics include:

- Determine the real dynamic amplification factor (DAF) to be used in load capacity assessment of bridges on non-HSR lines.

- Development of reliable and efficient structural models for predicting the dynamic response of bridges on HSR lines.

- Scrutinizing the current serviceability design limits for railway bridges on HSR lines as stated in the Eurocodes.

- Real-time monitoring of railway bridges as a tool for conditional assessments and damage detection.

- Finding novel bridge solutions for optimal for HSR.

A great deal of research already exists within most of the aforementioned topics. Future challenges consist of progressing beyond the state of the art as well as knowledge transfer between the academia and the industry. The aim is to achieve a safe, reliable and feasible implementation of the research in both assessment of existing railway bridges as well as in the design of new bridges on HSR lines.

This paper presents some examples of on-going research in both analysis and experimental testing of railway bridges, without any claim of giving a complete overview of the current state of the art.

\section{Dynamic analyses of railway bridges}

\subsection{Non-HSR}

For bridges on non-HSR lines, dynamic effects are most often accounted for by increasing the static response with a dynamic amplification factor (DAF). In the design of new bridges, EN 1991-2 states that Eq.(1) shall be used for the case of carefully maintained track, in combination with the design train load models LM 71, SW/0 and $\mathrm{SW} / 2$. Eq.(1) only depends on the so-called determinant length $L_{\Phi}$, which originally was derived from cases of simply supported beams, but is adopted for a large variety of structural components. Much of the work was done by the ORE in the 1960ies and 1970ies and was compared to experimental testing [5].

$$
D A F=\Phi_{2}=\frac{1.44}{\sqrt{L_{\Phi}}-0.2}+0.82, \quad 1.00 \leq \Phi_{2} \leq 1.67
$$

Eq (1) is often a rather crude simplification, to be used in conjunction with the equivalent design load models. When studying the effect from what is denoted 
as "real trains", EN 1991-2 instead refer to Eq (2). The factor $\varphi$ ' is due to the dynamic effects of the moving train load for non-resonant conditions and $\varphi^{\prime \prime}$ is the increase due to track defects and vehicle imperfections. When using "real trains" in fatigue assessment, the average dynamic effect, assuming a 100 year service life, may be used according to Eq. (3).

$$
\begin{gathered}
D A F_{R T}=1+\phi^{\prime}+0.5 \phi^{\prime \prime} \\
D A F_{F A T}=1+0.5 \phi^{\prime}+0.25 \phi^{\prime \prime}
\end{gathered}
$$

Research has shown that the dynamic amplification factors suggested by the codes may be over conservative. Especially in the assessment of existing structures, a more realistic prediction of the total train load effect may prove that more bridges can be upgraded to higher loads without expensive strengthening or replacement. [6]

\subsection{Design requirements, high-speed railways}

The design of railway bridges for HSR essentially follows similar procedure as for bridges on non-HSR. In addition however, a set of serviceability criterions regarding traffic safety and riding comfort are to be fulfilled, EN 1990 Annex A2. These criterions consist of limits for vertical deck acceleration, vertical displacements, end rotations and deck twist.

\subsubsection{Vertical deck acceleration}

In most cases where the bridge is susceptible to dynamic excitation, the vertical bridge deck acceleration will be decisive. This criteria exists to assure a sufficient track alignment and track stability, both from a maintenance and safety perspective. This phenomena was first discovered on the Paris to Lyon high-speed line, where a greater track maintenance than anticipated was required. Experimental testing with test trains at resonance speed showed adverse effects of the ballasted tracks at acceleration levels in the range $0.7-0.8 \mathrm{~g}$ in the bridge deck. Experimental shake table tests were later performed by [7], showing similar results. The effect owes to loss of ballast interlock and loss of contact friction, sometimes described as "floating ballast". Due to uncertainties in the real behaviour, a safety factor 2 was proposed. As a consequence, the current design limit in EN 1990 is $3.5 \mathrm{~m} / \mathrm{s}^{2}$ for ballasted tracks. For ballastless tracks, a limit of $5.0 \mathrm{~m} / \mathrm{s}^{2}$ exists, by adopting the safety factor 2 on the ground acceleration $g$. This is motivated by limiting the risk of rail-wheel contact and hence the risk of derailment. It is important to note that the acceleration is to be evaluated within a limited frequency range, in EN 1990 stated as the greater of $30 \mathrm{~Hz}, 1.5$ times the fundamental mode of vibration and the third mode of vibration. The experimental testing in [7] was done in the range $2-20 \mathrm{~Hz}$. Further research is needed on the dynamic behaviour of ballast, what frequency range to include and the influence of transient response. Research is also needed for the case of ballastless tracks, where the current limit of $5 \mathrm{~m} / \mathrm{s}^{2}$ seems as a rather crude simplification with little physical background. As comparison, the Chinese design codes for high-speed railway stipulate a set of running safety indices for the vehicle, as a derailment factor, offload factor, lateral wheel force and an overturn factor. These are used in conjunction with vertical dynamics from traversing train loads and transverse loads from strong wind [8].

\subsubsection{Vertical deck displacement}

EN 1990 also stipulate limits for vertical bridge deck displacement as an indirect measure to limit the vertical vehicle acceleration and thereby the passenger riding comfort. For bridges on non-high speed lines, the limit is set to $L / 600$ where $L$ is the span length. For higher speeds, the limit depends on the span length, the speed and number of consecutive spans and may range up to $L / 2600$. The Eurocode allows for separate vehicle/bridge interaction analysis if a more refined value for the vertical train acceleration is needed. No detailed information is however given on what vehicle configurations to assume or how the analysis should be performed. A somewhat confusing fact is that the vertical displacement should be determined based on the load model LM 71. In Japan, displacement limits with similar purpose is stipulated in [9], but is evaluated based on the Shinkansen high-speed train. There are some inconsistencies between the two codes, where EN 1990 is stricter for longer spans and [9] is stricter for shorter spans.

\subsubsection{Train load models}

The above mentioned serviceability criterions are compared to the dynamic response from passing trains, including resonance. Since this is not covered by the DAF-factors, a full dynamic analysis is often required. EN 1991-2 presented a series High-Speed Load Models to be accounted for. Except for simple structures, a total of 10 trains need to be analysed, denoted HSLM A1-A10. The train sets have different configurations with an axle load from $17-21$ tonnes and a total length of $370-$ $400 \mathrm{~m}$. The HSLM load model is designed to account for common high-speed trains in Europe. The resulting envelope may therefore be significantly larger than the response from a single existing train type. This will enable interoperability between different countries but may require a less optimal design. This may also be an obstacle in upgrading existing conventional lines to highspeed standard. Using the so-called train signature method [10] the dynamic load effect of particular trains can be compared, regardless of bridge type.

An example of this is shown in Figure 2, where the wavelength $\lambda=v / f_{0}$ for the train speed $v$ and the fundamental frequency $f_{0}$ of the structure. The train signature parameter $S_{0}$ is obtained by a Taylor series expansion, further explained in [10]. Figure 2 show that the envelope of HSLM-A in many cases far exceeds the load effect from existing real trains in Sweden. 


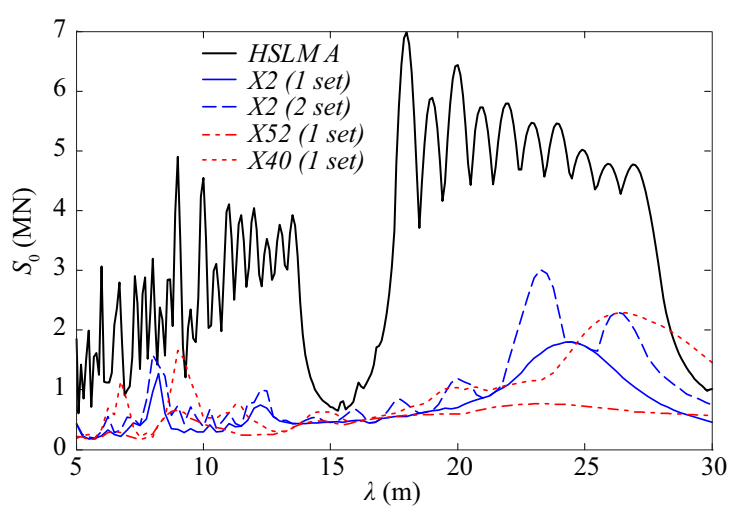

Figure 2. Train signature for train load model HSLM A and common passenger trains in Sweden, reproduced from [11].

\subsection{Structural models}

To enable realistic predictions of the real dynamic bridge response, the choice of structural model is of paramount importance. Increased level of detail may improve the results, if sufficient input data are available. Since a large set of simulations usually is required, a trade-off between accuracy and computational time is sometimes required. For simply supported 2D Euler-Bernoulli beams on fixed supports, closed form solutions have been developed by [12]. A closed form solution for the dynamic response of continuous beams with variable stiffness on elastic supports is presented in [11] and [13].

\subsubsection{Portal frame bridges}

The same model as in [13] was used to predict the dynamic response from portal frame bridges, Figure 3. Sufficient agreement was obtained when comparing the response to a full 3D-model [14]. The support conditions were based on 3D-models of the vertical walls, wing walls and foundation slab, see Figure 4. The resulting vertical stiffness $k_{\mathrm{v}}$ and rotational stiffness $k_{\mathrm{r}}$ was included in the simple model. The additional mass from the substructure is included either as a lumped mass $m_{2}$ or as a short element $L_{2}$ with increased density.

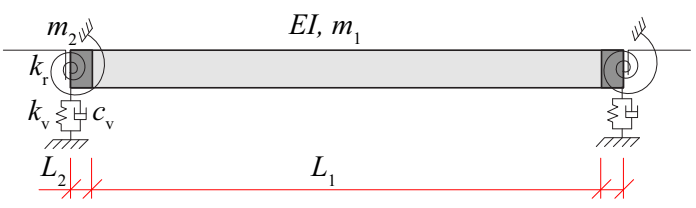

Figure 3. Simple 2D beam model for a portal frame bridge, accounting for SSI, based on [11] except the inclusion of $c_{\mathrm{v}}$.

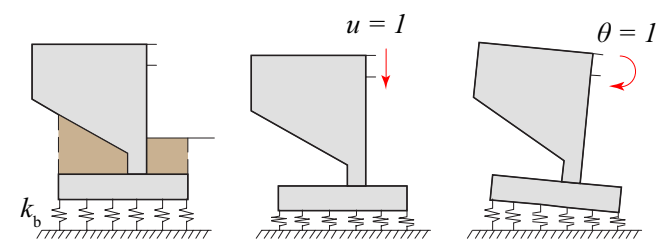

Figure 4. Substructure to determine the support stiffness, reproduced from [15].
The Soil-Structure Interaction (SSI) between the frame bridge and the adjacent backfill material is not trivial. For the case of a slab on a semi-infinite soil, charts of impedance functions were developed by [16]. The resulting stiffness and damping components may be seen as frequency dependent. This concept was used by [17], see Figure 5.

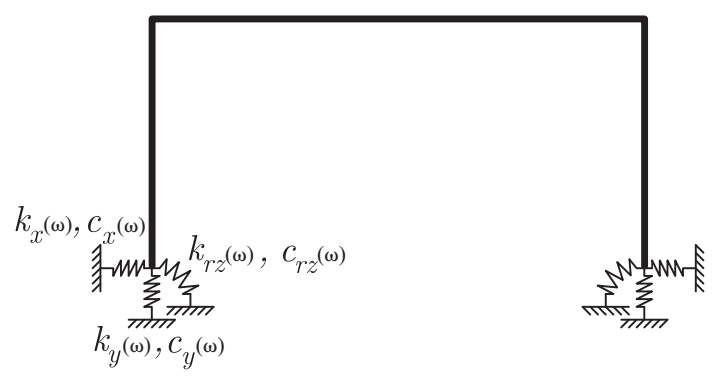

Figure 5. 2D frame model of a portal frame bridge with frequency dependent boundaries, reproduced from [17].

Another approach is to model the surrounding soil directly, Figure 6. Even for a 2D-approach, the computational time increases significantly compared to simple 2D frame/beam models. Great care must also be taken to the boundaries, to avoid unwanted reflecting waves and spurious vibrations. This can be achieved by what is sometimes denoted as silent boundaries. Different strategies exist, e.g. using elements with similar properties as the adjacent soil but with increased material damping, using a set of optimal springs and dashpots, infinite elements or boundary elements. In the case of shallow foundations, Figure $6 \mathrm{~b}$, reflecting waves may be expected and fully fixed boundaries may be motived.

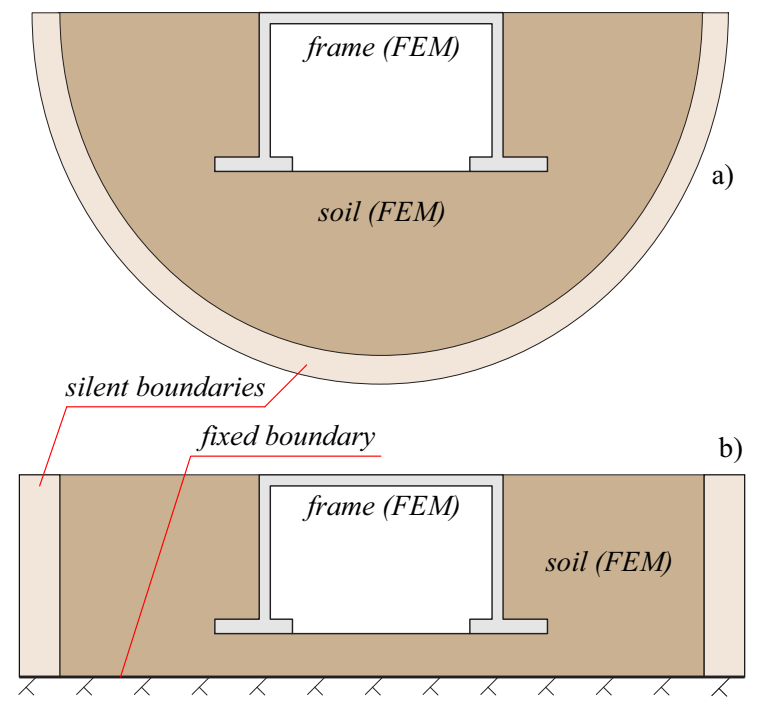

Figure 6. 2D approach for full SSI of a portal frame bridge, a) half-space model for deep foundations, b) vertical constraints for shallow foundations.

If plate modes or other 3D effects are expected, a full 3D model similar to Figure 7 may be required. Accounting for the SSI only as a vertical stiffness under the foundation slab may be a crude simplification. Extending the concept of Figure 6 in 3D usually result in a significant increase in computational time. 


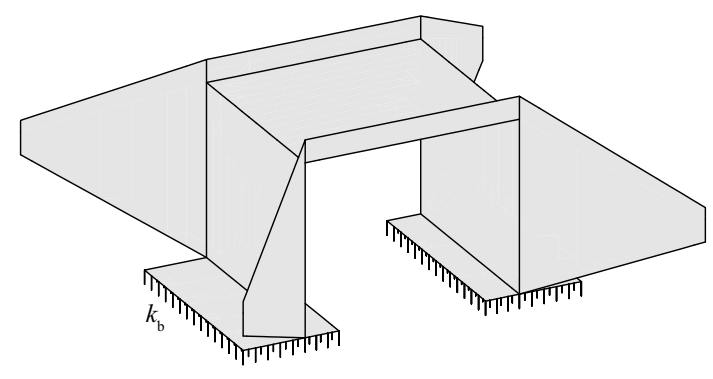

Figure 7. 3D shell model of a portal frame bridge, accounting for foundation support stiffness.

In Figure 8, simulation results from a $6.5 \mathrm{~m}$ single track portal frame bridge is presented. The peak vertical deck acceleration from an ICE3-train is calculated at speeds varying from 100 to $400 \mathrm{~km} / \mathrm{h}$. A 2D-model similar to Figure 6 was used. A model only accounting for the vertical support stiffness, denoted "no SSI" suffers from resonance at about $325 \mathrm{~km} / \mathrm{h}$ with a resulting acceleration of $6 \mathrm{~m} / \mathrm{s}^{2}$. For the present case, assuming either a half-space or a shallow foundation depth results in a significant decrease in acceleration. The model in Figure 3 may have been able to produce similar results, provided a suitable value for $c_{\mathrm{v}}$.

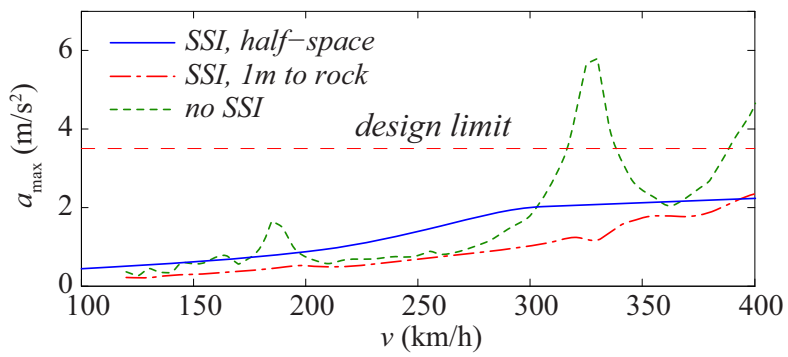

Figure 8. Influence of soil-structure interaction, case of a single track portal frame bridge with a span of $6.5 \mathrm{~m}$. [18]

\subsubsection{Live load distribution}

In design, the load from the train can be distributed to the deck via three sleepers according to Figure 9. The track may instead be assumed to work as a Winkler bed, or as in the case of Figure 10 as a continuous beam on elastic supports. The support reactions are presented in Figure 11 for a rail seat stiffness of $150 \mathrm{MN} / \mathrm{m}$ and a sleeper distance $s=0.65 \mathrm{~m}$. A triangular projection of the load distribution with a length of $3 \mathrm{~m}$ is suggested, [11]. The dynamic response from passing trains can in many cases be significantly reduced by accounting for the load distribution of the track, especially for shorter spans.

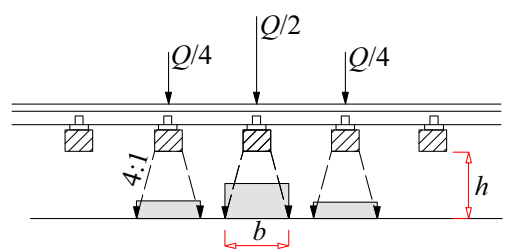

Figure 9. Load distribution from a single axle $Q$ used in design, reproduced from [19].

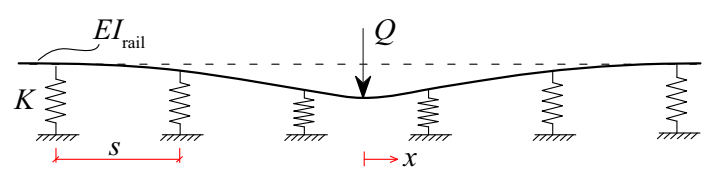

Figure 10. A continuous 2D beam on elastic supports, illustrating the deformed track under a single axle load $Q$ [reproduced from [14].

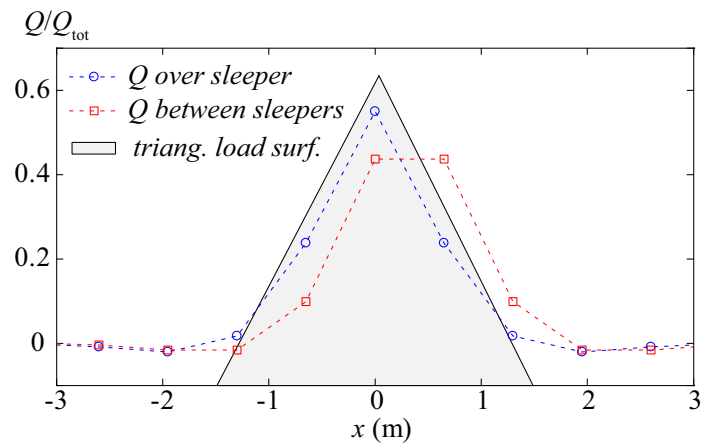

Figure 11. Load distribution from a single axle load, based on a Winkler-bed model with $K=150 \mathrm{MN} / \mathrm{m}$. Reproduced from [14].

\subsubsection{Train-Bridge Interaction}

Each axle of the train is often simplified as a vertical point load. The Train-Bridge Interaction (TBI) may however mitigate part of the vibrations due to the primary suspension system, Figure 12. This effect was studied in [10]. Including the sprung-mass system of the train increases the level of complexity in the analysis, motivating the need for a simpler approach. The result was to account for the TBI by an additional damping of the structure, $\Delta \zeta$, which is currently included in EN19912 [19].

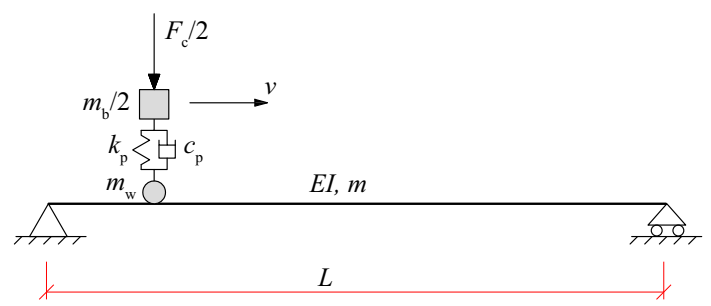

Figure 12. Sprung-mass system of a single axle traversing a simply supported beam, reproduced from [4].

The TBI is illustrated in Figure 13, consisting of a simply supported beam with a span of $10 \mathrm{~m}$, a fundamental frequency of $9.7 \mathrm{~Hz}$ and a mass 10 tonnes/m, subjected to an ICE2 train model. Good agreement is found when comparing the result from the sprung-mass model with moving point loads, where the latter includes the additional damping $\Delta \zeta$. Similar results were obtained by [20] for the same case. The formulas in EN 1991-2 are mainly intended for simply supported bridges. A study of the applicability for portal frame bridges was performed by [4], which showed that the additional damping in EN 1991-2 may be nonconservative. 


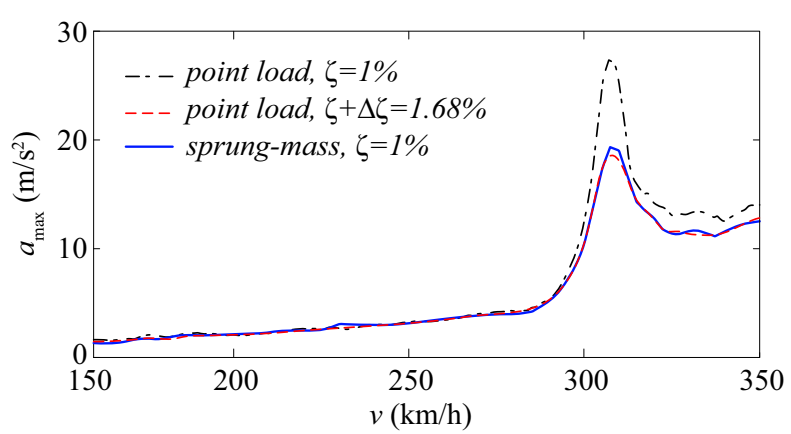

Figure 13. Case of a simply supported bridge, comparison between point loads, additional damping and the sprung-mass model, reproduced from [4].

\subsubsection{Nonlinear behaviour}

The dynamic design checks for HSR bridges mainly comprise a set of serviceability criteria and the analysis is therefore assumed to be linear. Several sources of nonlinearities may however still exist, e.g.:

- concrete cracking [21]

- ballast behaviour [22]

- supports and bearings [23]

- temperature and seasonal variation [24]

- amplitude dependencies [25].

\subsection{Feasibility study for upgrading existing lines to HSR}

To get an overview of the dynamic performance of railway bridges for HSR, the results from a feasibility study is presented. Further results are found in [15] and [26]. It shall be noted that the study only comprise theoretical simulations and no experimental testing.

The aim of the study was to estimate if it would be possible to upgrade the existing railway lines between Stockholm - Gothenburg and Malmö, Figure 14, to higher speeds. The target was a design speed of $250 \mathrm{~km} / \mathrm{h}$, compared to today's standard of 70 - to $200 \mathrm{~km} / \mathrm{h}$. Three routes were investigated:

- Stockholm - Gothenburg: 500 km, 400 bridges,

- Stockholm - Malmö: 600 km, 350 bridges,

- Gothenburg - Malmö: 280 km, 270 bridges.

In total, more than 1,000 railway bridges needed to be analysed, corresponding to about $25 \%$ of the total railway bridge stock in Sweden. To handle the vast amount of bridges, an analytical 2D model was used. For each bridge, basic data on span length, material and bridge type was available. Data on bridge mass, deck stiffness and foundation stiffness was however not available. Due to the uncertainties, a probabilistic approach was used. The bridges were categorised in different groups with similar design and prediction bounds for the random variables were determined based on a selection from each group. Monte-Carlo simulations were performed for each individual bridge, based on deterministic base data and probability distributions for the random variables. The probability $p_{\mathrm{f}}$ of exceeding the vertical deck acceleration $3.5 \mathrm{~m} / \mathrm{s}^{2}$ was then estimated. The train load consisted of HSLM A1-A10 at speeds from $100 \mathrm{~km} / \mathrm{h}$ to 1.2 times the design speed, hence $300 \mathrm{~km} / \mathrm{h}$. In total, about 40,000 simulations per bridge were performed.

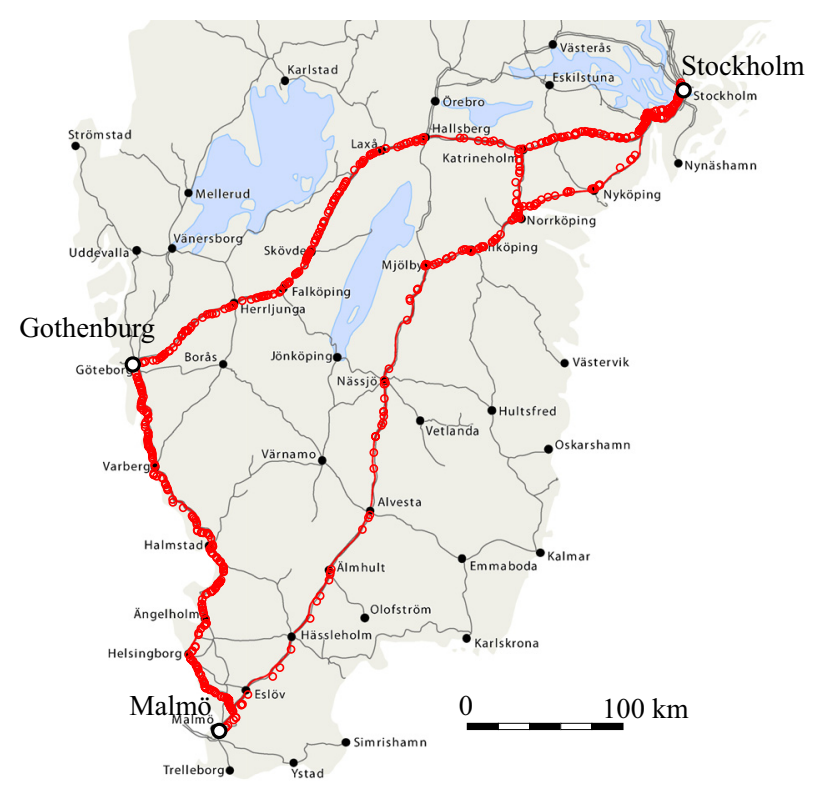

Figure 14. Map of South of Sweden, illustrating the bridges included in the feasibility study, reproduced from [14].

The bridge stock consists of about 500 portal frame bridges, whereof about 270 are designed as closed box culverts. The second most common group are slab- and beam bridges, in total about 430 bridges whereof more than 280 are designed as simply supported. The remaining bridges are arch bridges (65), corrugated steel culverts (10) and truss and open deck bridges (15). The current 2D model is deemed insufficient to describe the dynamic behaviour of the latter groups.

Further, about $90 \%$ of the bridges consist of concrete, $5 \%$ of steel and $5 \%$ of stone. About $45 \%$ have a span less than $6 \mathrm{~m}$ and $45 \%$ within 6 to $21 \mathrm{~m}$. $70 \%$ are single span bridges, $5 \%$ two span and $10 \%$ three span. Many bridges were replaced when the lines were upgraded to double track in the 1950 'ies, and only $5 \%$ of the existing bridges were built before 1940 . Some $55 \%$ are less than 35 years old.

The random variables consist of the bridge deck stiffness, bridge deck mass and the foundation stiffness. The geometry of a selection of bridges was studied, from which the prediction bounds could be estimated. The relation between span length and fundamental natural frequency for the beam bridges are shown in Figure 15. Many of the samples lies outside the recommended boundaries according to EN 1991-2 and some of these bridges are expected to suffer from large dynamic effects from passing trains. A similar prediction bound is determined for the bridge deck mass, including the ballasted track but not the foundation. 


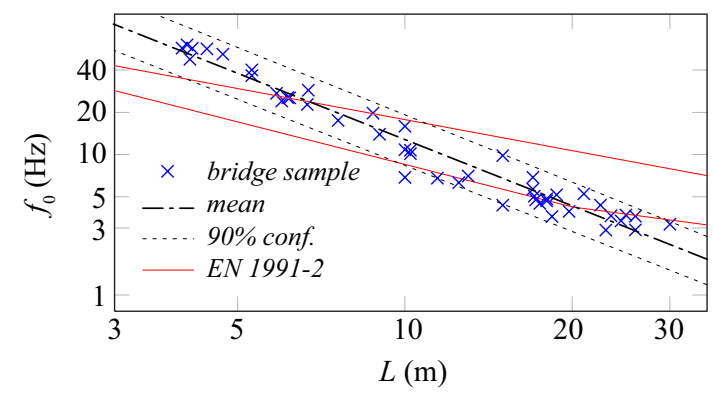

Figure 15. Relation between span with and first natural frequency for beam bridges based on calculations, reproduced from [14].

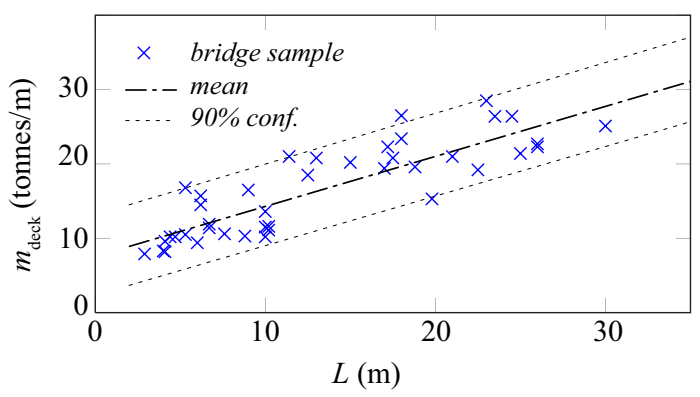

Figure 16. Relation between span with and mass of the beam bridge deck, based on calculations, reproduced from [14].

Figure 17 shows the probability of exceeding the acceleration limit $3.5 \mathrm{~m} / \mathrm{s}^{2}$ for portal frame bridges. In total, about $65 \%$ of the closed portal frame bridges and $40 \%$ of the open portal frame bridges showed a probability $p_{\mathrm{f}}>0.5$ to exceed the acceleration limit. The corresponding value for the beam bridges are about $70 \%$. The high rate of failure may partially be due to oversimplified models and conservative assumptions. For portal frame bridges and short span decks, the additional damping $c_{\mathrm{v}}$ due to SSI may be significant. However, shorter decks may show significant 3D behaviour in terms of plate modes that can increase the vibrations significantly. An unknown number of bridges are also designed with a larger over-sail at the supports, which in a simplified analysis results in much larger dynamics compared to a counterpart without over-sail.

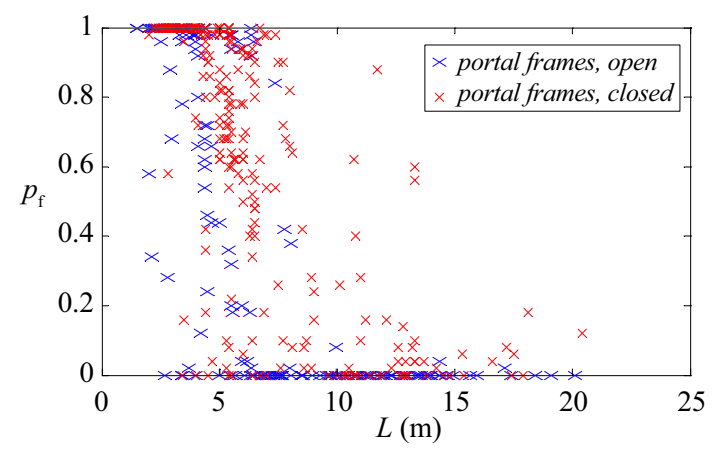

Figure 17. Probability of exceeding the design acceleration $3.5 \mathrm{~m} / \mathrm{s}^{2}$, based on data from [14].

\subsection{Performance check for an existing HSR line - desk study}

A second theoretical study has been performed on a newly built railway line in North of Sweden, Figure 18 [15]. The construction work started in 1999 and the whole line was finalised in 2010. The total distance is $190 \mathrm{~km}$ single track and consists of 76 railway bridges, whereof 34 portal frame bridges, 33 concrete beam/slab bridges and 9 steel-concrete composite bridges.

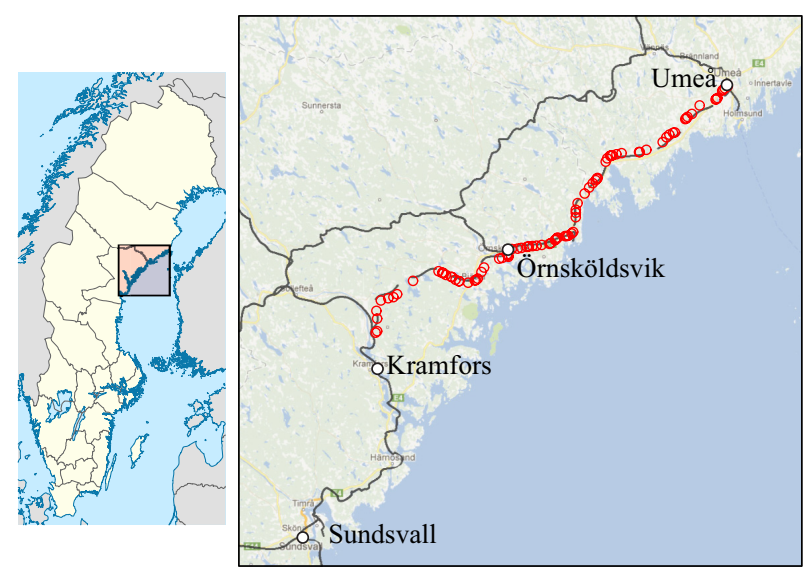

Figure 18. Map of North of Sweden, illustrating the bridges included in the desk study, reproduced from [15].

The bridges are designed for freight trains with 33 ton/axle and passenger trains up to $250 \mathrm{~km} / \mathrm{h}$. The serviceability criteria for HSR were not adopted in Sweden until 2004, when many of the bridges on the line had already been designed. As a consequence, many bridges were subjected to dynamic assessments after they were built. Depending on the choice of structural model and input parameters, the results from a dynamic analysis may scatter significantly.

To get on overview of the dynamic performance, all bridges were analysed using similar models as in the previous feasibility study. For each bridge, data regarding span lengths, support conditions, bridge deck mass and stiffness was determined directly from the drawings. For the portal frame bridges the support stiffness was determined based on the each individual substructure and assuming a bed modulus of $100 \mathrm{MN} / \mathrm{m}^{3}$ but no additional damping due to SSI. For the remaining beam- and slab bridges the vertical supports were assumed fixed.

The first fundamental natural frequency of the bridges is shown in Figure 19. Many of the portal frame bridges lies below the lower recommended limit in EN 1991-2. The main reason for this is due to the assumed vertical support stiffness, where the first mode for many of the shorter bridges is governed by a rigid body motion.

For each bridge, the response from train load model HSLM A1-A10 was analysed within the speed range of 100 to $300 \mathrm{~km} / \mathrm{h}$. A load distribution according to Figure 9 was used.

The peak acceleration for each bridge is presented in Figure 20. The results show that the design limit for vertical deck acceleration is exceeded for $75 \%$ of the portal frame bridges, $40 \%$ of the beam bridges and $45 \%$ 
of the steel-concrete composite bridges. It should be stressed that the results are based on a rather simplified and possibly over-conservative model. The portal frame bridges are likely to mitigate a significant part of the vibrations due to SSI. Similar effects may be expected for the beam bridges with large over-sail. Some of the steelconcrete composite bridges may however constitute a real problem with dynamics, especially for simply supported spans.

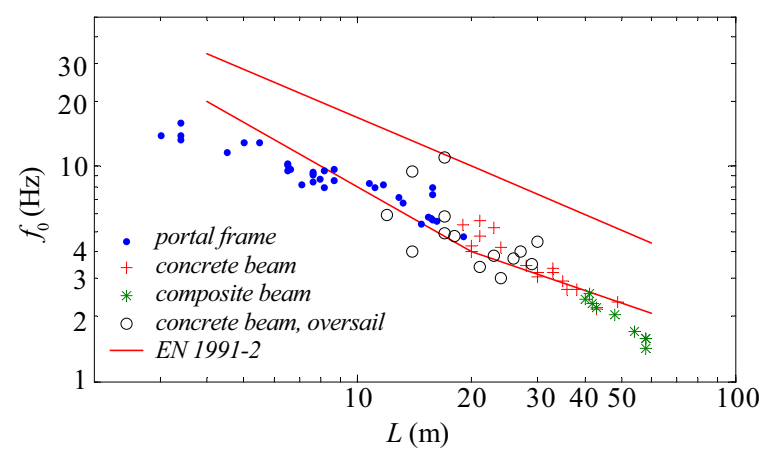

Figure 19. Relation between span length $L$ and first natural frequency $f_{0}$ for different bridge types, based on data from [15].

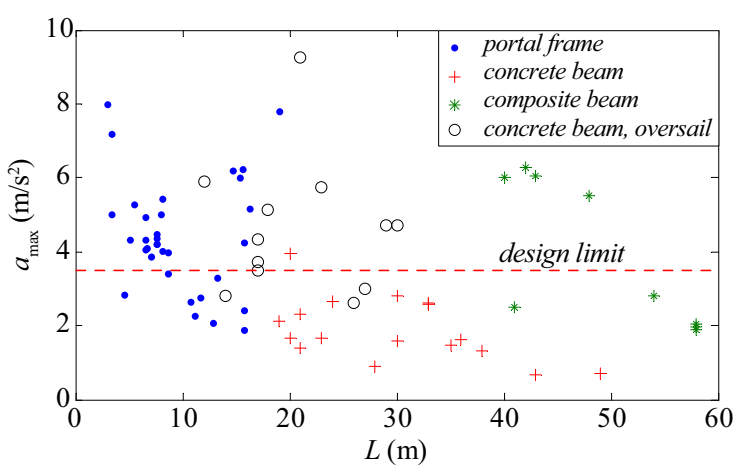

Figure 20. Peak vertical acceleration for the studied bridges, based on data from [15].

One of the bridges showing excessive deck acceleration is a simply supported concrete slab bridge at Aspan, Figure 21. The span length is $24 \mathrm{~m}$ and the oversail at each support are $1.7 \mathrm{~m}$.

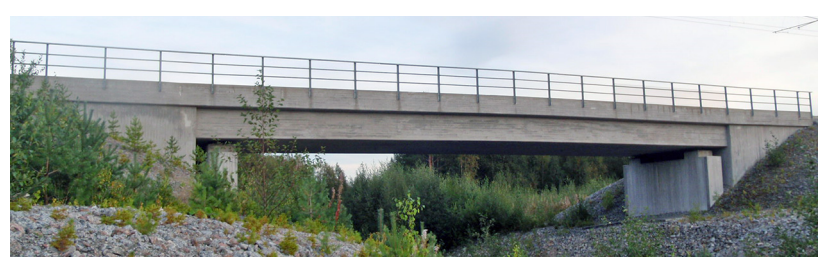

Figure 21. A simple supported beam bridges with integrated backwalls at Aspan.

Experimental testing was performed in 2005, before the ballasted track was in place [27]. From the experiment, the first vertical bending mode was $6.9 \mathrm{~Hz}$ with an appertaining damping of $1 \%$. In the 2D-model, the mass of the ballasted track was included and the stiffness of the concrete was reduced with $0.6 E_{\mathrm{cm}}$ to account for future cracking. The first natural frequency from the $2 \mathrm{D}$ model is $3.1 \mathrm{~Hz}$ and the assumed damping is
$1.6 \%$. A 3D-model of the bridge was developed and the SSI at the integrated back walls was accounted for using solid elements for the soil, assuming $E_{\text {soil }}=200 \mathrm{MPa}$. The models are not described in great detail in this paper, but the results in Figure 22 shows the potential of including SSI for bridges with integrated back walls and large oversail. The first vertical bending mode of the $3 \mathrm{D}$ model is $3.6 \mathrm{~Hz}$ without SSI and $5.4 \mathrm{~Hz}$ with SSI. In both cases, a damping of $2 \%$ was assumed. To verify the real performance of the bridge, additional experimental testing is needed.

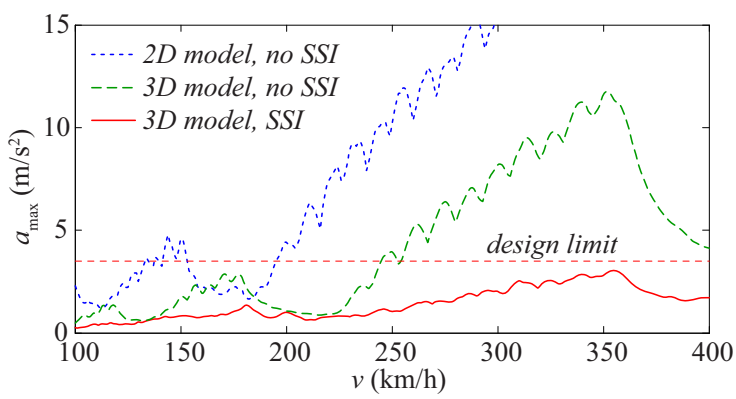

Figure 22. Simulation results for the beam bridge at Aspan, comparison of initial 2D-model and different 3D-models.

\section{Verification by field tests}

The above presented case studies were based solely on theoretical models without experimental verification. Many of the bridges that were deemed to exceed the limit for vertical deck acceleration may in reality show significantly less vibrations. To prove that more bridges fulfil the dynamic criterion, extensive experimental testing is required.

Experimental data serve as valuable input in understanding the real structural manner of action of the bridges and for updating or revising the proposed structural models. The main characteristics to be determined consist of natural frequencies, mode shapes and damping ratios. In addition, non-linear effects as listed in section 2.3.4 may be studied further. In the following, some case studies of experimental testing on railway bridges are presented.

\subsection{Case study 1 - A portal frame bridge}

The first case study is a portal frame bridge at Orrvik, Figure 23, located along the Bothnia Line presented in section 2.5. Based on the simple 2D-model, a peak acceleration of $6.0 \mathrm{~m} / \mathrm{s}^{2}$ was calculated at a critical train speed of $286 \mathrm{~km} / \mathrm{h}$. The span length is $15.2 \mathrm{~m}$ and the first natural frequency was calculated to $5.9 \mathrm{~Hz}$. Experimental results from passing trains are reported in [28], but no clear information on the natural frequencies or damping is presented.

The experiments were performed during high-speed tests with the Green Train [29]. The speed record for the Green train is $303 \mathrm{~km} / \mathrm{h}$, but during the bridge test the highest speed was about $280 \mathrm{~km} / \mathrm{h}$.

Accelerometers were mounted on top of the edge beams, $1.5 \mathrm{~m}$ from mid-span. The peak acceleration 
during the train passages at different speeds are plotted in Figure 24. The measured acceleration is subjected to a low-pass filter at first $90 \mathrm{~Hz}$ and the $30 \mathrm{~Hz}$. A 2D frame model proposed by [28] shows overall reasonable agreement for the case of $90 \mathrm{~Hz}$ frequency range. The acceleration magnitude is decreased significantly when using a $30 \mathrm{~Hz}$ filter.

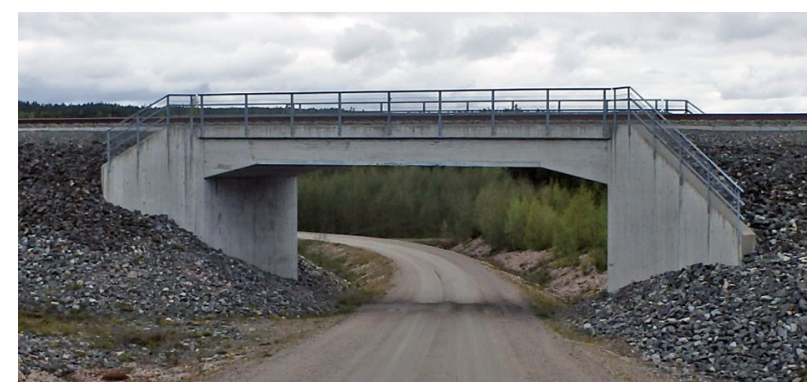

Figure 23. The portal frame bridge at Orrvik.

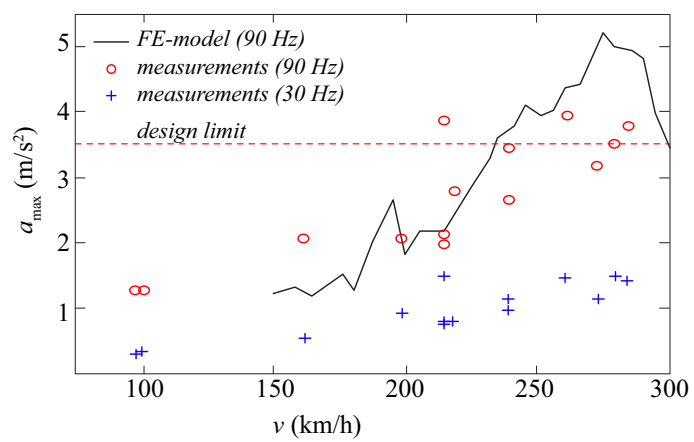

Figure 24. Peak vertical deck acceleration during passage of the test train at different speed (gröna tåget), comparison between experimental testing and simulation results, based on [28]

\subsection{Case study 2 - Steel-concrete composite bridge}

The second case study is a $36 \mathrm{~m}$ simply supported single track steel-concrete composite bridge, at Skidträsk, about $190 \mathrm{~km}$ North of Umeå. The bridge is designed for freight trains with 25 tonnes/axle but not for high-speed trains. A long-term monitoring system was installed for continuous monitoring of deck acceleration and strain in the steel beams.

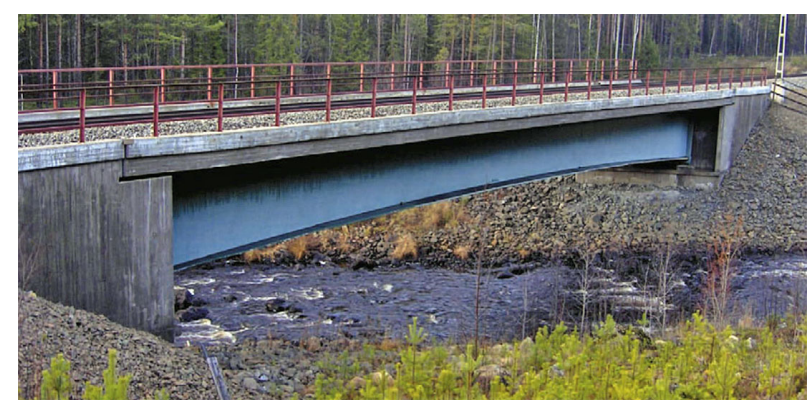

Figure 25. The portal frame bridge at Skidträsk, reproduced from [24].

In [24], the change in dynamic properties due to seasonal changes was studied. A significant increase in natural frequency was discovered during the winter period, both for the first vertical bending mode and the first torsional mode, Figure 26.

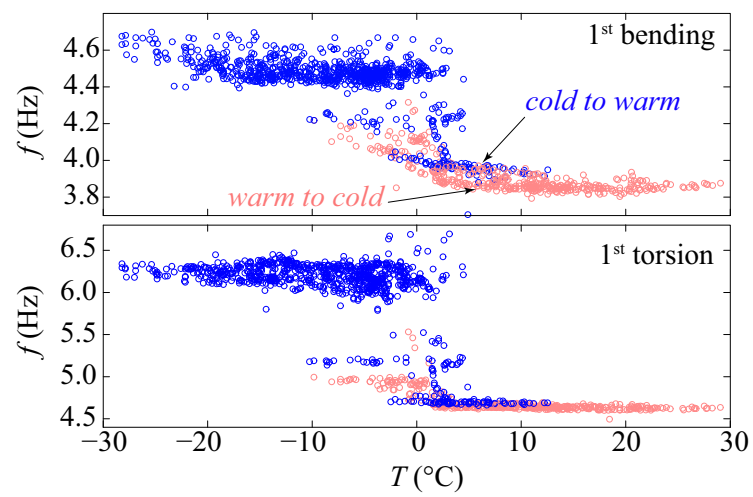

Figure 26. Influence of the temperature on the first bending and torsional mode of the unloaded bridge, reproduced from [24].

A 3D FE-model was developed, including relevant SSI components from both the ballasted track and the substructure. Distribution functions for the variation of concrete stiffness, ballast stiffness and foundation stiffness was assumed and a Bayesian model update technique was used to find plausible matches between the model and the experimental data. The results showed that the change in vertical bending frequency is mainly governed by the foundation stiffness, whereas the change in torsional frequency is mainly governed by the ballast stiffness. The model proposed that the E-modulus of the ballast would increase from $180 \mathrm{MPa}$ in the summer to $1500 \mathrm{MPa}$ in the winter. The corresponding increase in the foundation was from $75 \mathrm{MPa}$ to $110 \mathrm{MPa}$. The model did not propose any change in E-modulus for the concrete.

The response from passing trains on the same bridge is presented in [25]. Based on the measured free vibrations after train passages, a change in both natural frequency and damping was observed. The ballasted track was believed to be the main source of this non-linear behaviour. Later studies of the mechanism of bearings [23] do however suggest that the hysteresis behaviour of roller bearings may have a significant impact in the dynamic response of the bridge. For low amplitude vibrations, the roller bearings are expected to act as fixed.

\subsection{Case study 3 - Soil-Steel composite bridge}

The third case study is a corrugated steel culvert in Märsta, about $40 \mathrm{~km}$ North of Stockholm. Corrugated steel culverts are statically designed accounting for composite action with the surrounding soil but its performance during dynamic loading is not readily known. The studied bridge serves as a pedestrian underpass, Figure 27, and has an elliptical section with a horizontal diameter of $3.75 \mathrm{~m}$ and a vertical diameter of $4.15 \mathrm{~m}$. The fill height at the crown is about $1.9 \mathrm{~m}$ and carried two tracks. The line consists of mixed train traffic with both medium heavy freight trains ( $\max 22.5$ tonnes/axle) and various commuter and long distance train (with speeds up to $170 \mathrm{~km} / \mathrm{h}$ ). 


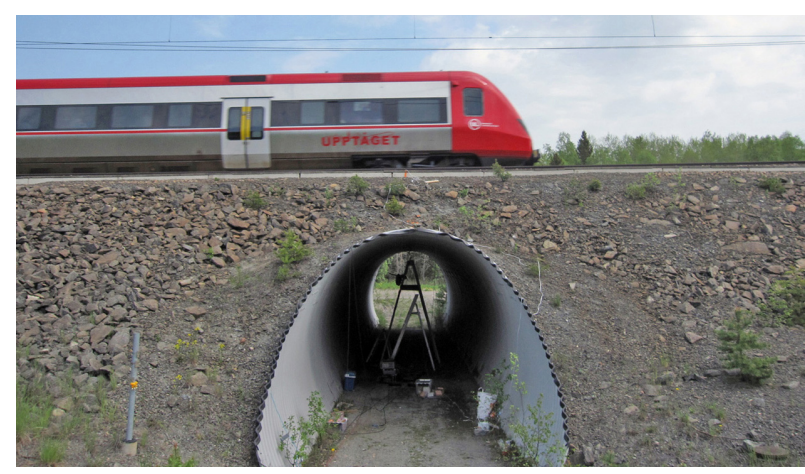

Figure 27. The soil-steel composite bridge at Märsta during passage of an X52 train, reproduced from [30].

The bridge was instrumented with displacement transducers, accelerometers and strain gauges. The main aim of the measurements was to gain further understanding of the dynamic behaviour during train passages and if they would be suitable for HSR. A small part of the instrumentation is shown in Figure 28.

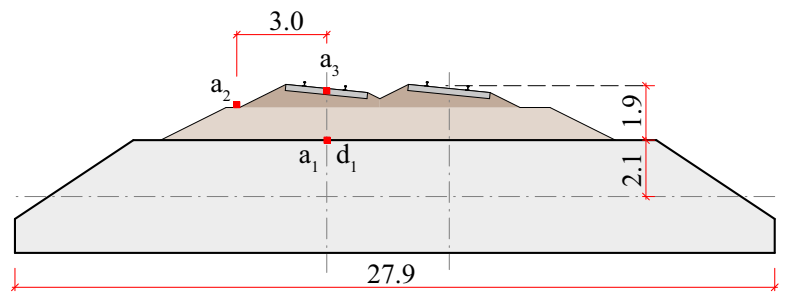

Figure 28. Cross-section of the bridge at the crown, illustrating part of the instrumentation, reproduced from [30].

The peak acceleration from a number of passing trains is shown in Figure 29, after applying a $30 \mathrm{~Hz}$ low-pass filter. For conventional slab-like bridges, the vertical deck acceleration is an indirect measure of the allowable vibration of the track. It is therefore of interest to investigate the relation between the acceleration of the steel pipe to the acceleration in the track zone. Train model X52, similar to the Green Train, pass the bridge at about $170 \mathrm{~km} / \mathrm{h}$ in most cases. The acceleration $\mathrm{a}_{1}$ in the steel pipe appears well correlated to the acceleration $a_{2}$ at the ballast shoulder. Acceleration $a_{3}$ in the ballast within the track zone does however scatter significantly. Values with $\mathrm{a}_{\max }<0.4 \mathrm{~m} / \mathrm{s}^{2}$ is due to trains passing on the opposite track.

A 3D FE-model of the bridge have been developed as an extension of Figure $6 \mathrm{~b}$. A similar version of the model is found in [31]. A comparison between the model and the experimental results are shown in Figure 30. A manual model update is performed, primary focusing on the soil stiffness and the soil-steel interaction. The presented results are based on full contact with no slip between the soil and the steel. Further, $E_{\text {soil }}=120 \mathrm{MPa}$ is used. This results in good agreement with the vertical displacement $\mathrm{d} 1$ at the crown, but underestimates the acceleration $a_{1}$ and overestimates the acceleration $a_{3}$. It shall be noted however, that the measured acceleration scatters significantly.
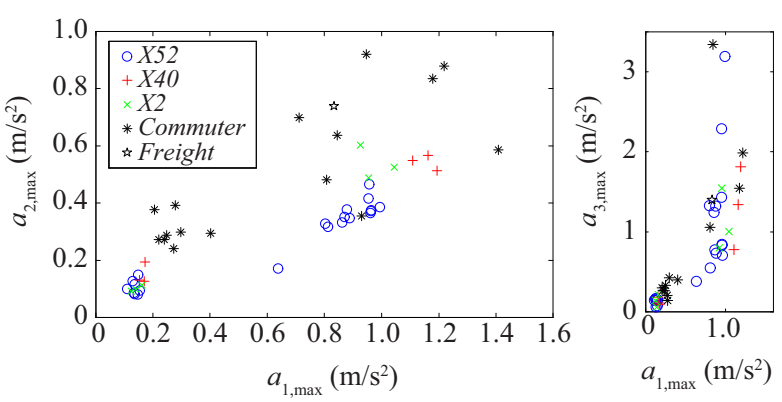

Figure 29. Peak acceleration from passing trains, $a_{1}$ inside the steel pipe, $a_{2}$ at the ballast shoulder, $a_{3}$ in the ballast between the sleepers [30].

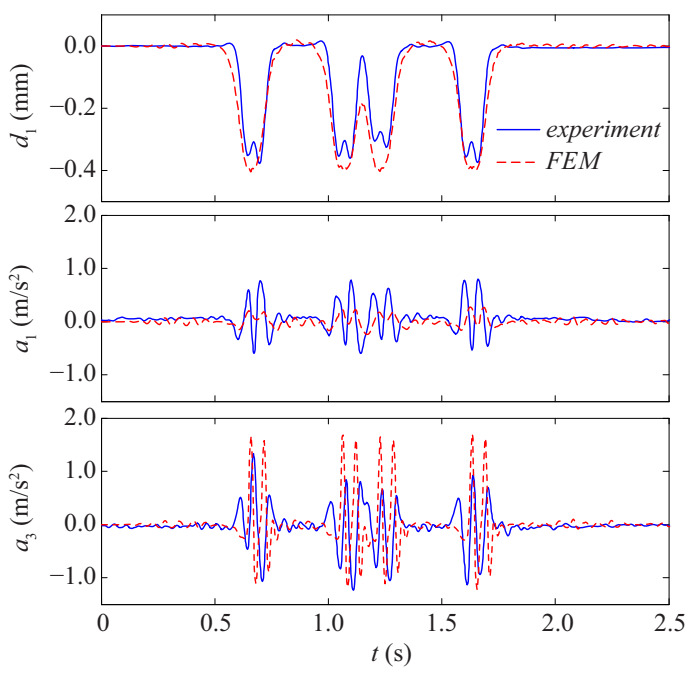

Figure 30. Comparison between measured response and dynamic simulation using a 3D model with full SSI, X52 train at $170 \mathrm{~km} / \mathrm{h}$.

\subsection{Case study 4 - Multi-span concrete slab bridge}

The last case study comprise controlled excitation of a three-span two track concrete bridge in Södertälje, $35 \mathrm{~km}$ South of Stockholm. The side spans are $11.1 \mathrm{~m}$ and the mid-span $18.4 \mathrm{~m}$. The bridge was part of the feasibility study reported in [14]. From the simplified 2D analysis, excessive accelerations were predicted, owing to the integrated back-walls with $3.0 \mathrm{~m}$ over-sail. A view of the bridge is shown in Figure 31.

A hydraulic bridge exciter has recently been developed and the presented bridge serves as a first fullscale pilot test. The concept of the hydraulic exciter is to apply a constant amplitude load with variable frequency at the bridge soffit. Testing can therefore be performed without closing the track and the mass of the exciter equipment does not influence the bridge response. The system essentially consists of a support plate, a hydraulic load cylinder and a truss frame that is pre-stressed against the bridge soffit. A photo of the system when installed on the bridge is shown in Figure 32. The force is monitored by a load cell at the upper connection to the bridge and an MTS FlexTest SE controller assures that constant load amplitude is achieved. The system is able to account for flexibility in both the test frame and the foundation. The 
load cylinder has a capacity of $50 \mathrm{kN}$. The system works in compression, enabling load amplitudes up to $25 \mathrm{kN}$. The system is designed for a working range up to $50 \mathrm{~Hz}$, but can be increased for lower displacement amplitudes.

Although the load capacity is less than a conventional train axle load, the main advantage is that the excitation can be controlled in both load and frequency. The bridge exciter is expected to enable relatively high amplitude vibrations, since the steady-state response can be obtained. Further, experimental frequency response functions (FRF) can be obtained with high accuracy, serving as valuable input for model updating and structural identification. Further details on the bridge exciter and the pilot test are presented in [32] and [33].

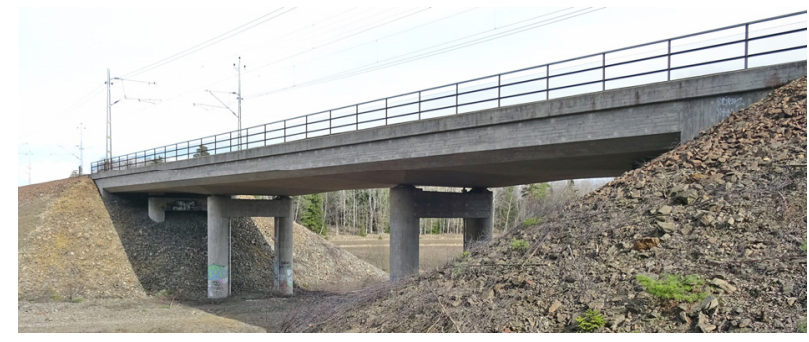

Figure 31. The beam bridge at Pershagen. [32]

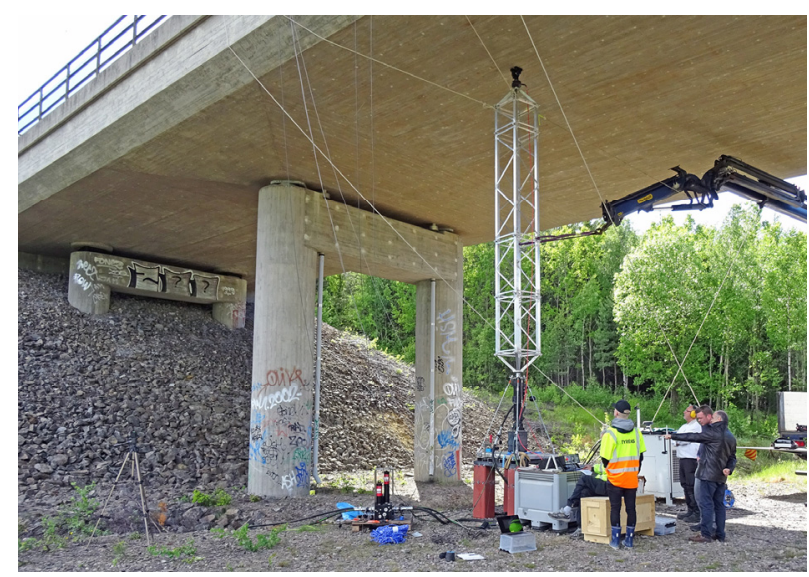

Figure 32. The beam bridge at Pershagen, during testing with the hydraulic exciter, [32]

A 3D FE-model of the bridge have been created, further described in [32]. The experimental testing revealed a total structural damping of $1.7 \%$ for the $1^{\text {st }}$ mode and $2.5 \%$ for the $3^{\text {rd }}$ mode, which was used in fitting a Rayleigh material damping in the model. However the experiments showed that the $2^{\text {nd }}$ mode was significantly more damped, in the order of $7-9 \%$. The reason for this is not readily known. As a consequence, the model will overestimate the response from the $2^{\text {nd }}$ mode. A comparison of the FRF between the experiment and the model is shown in Figure 33. Good match is found for the first mode, both in frequency and amplitude. As expected, the model overestimates the amplitude of the $2^{\text {nd }}$ mode but with good agreement in frequency. A slight shift in frequency is seen for the remaining part of the FRF, which may be refined by additional model updating.

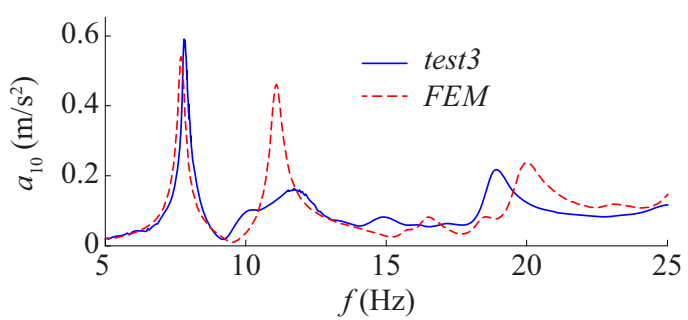

Figure 33. FRF at mid-span, comparison between experimental results and the 3D FE-model. [32]

The FE-model is finally used to predict the dynamic response from passing trains. The envelope of HSLM A1-A10 at different speed is presented in Figure 34. SSI is considered by modelling the soil material in contact with the integrated back wall, assuming $E_{\text {soil }}=200 \mathrm{MPa}$. Unlike the model of Aspan, section 2.5, the stiffness of the soil has only a minor influence of the natural frequencies.

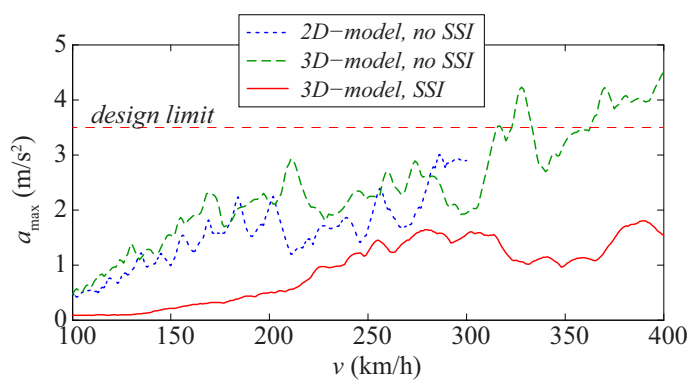

Figure 34. Peak vertical deck acceleration from HSLM A1A10, comparing different simulation models.

\section{Discussion and conclusions}

In this paper, different aspects of railway bridge dynamics have been discussed. The success in predicting the real dynamic response highly depends on the choice of structural model. An increased level of detail may improve the results, but reliable input data are not always available. On the other hand, simplified models may prove sufficient and sometimes with similar accuracy as far more complicated models, provided that the main governing features of the real response can be described.

One way of dealing with uncertainties is by probabilistic approaches. Based on a simple structural model, the dynamic performance of a large number of railway bridges were estimated in [26]. Although the specific numbers for each bridge is afflicted with great uncertainties, it may serve as a first ranking of the bridges and for an early stage cost estimate when considering upgrading of existing lines. A probabilistic approach was also used by [34].

The dynamic response of railway bridges on HSR lines is limited by a set of serviceability criteria. Some of these, e.g. the vertical deck acceleration, may sometimes be over conservative. More accurate design limits may result in the use of slender bridges and enabling upgrading of more existing bridges to higher speeds, with a required safety limit. 
Increased understanding of the real dynamic manner of action by controlled experimental testing can hopefully result in more accurate predictions of the dynamic response and model updating and hence less need for safety margins in the models.

Despite an ever increasing computational capacity, large models are still time consuming, especially in combination with Monte-Carlo simulations and probabilistic approaches. To fully account for SSI is also often time consuming and finding simplified approaches with sufficient accuracy may be necessary.

\section{Acknowledgements}

The authors which to thank the Swedish Transport Administration (Trafikverket) for funding part of the experimental tests and the feasibility studies. The instrumentation of the Märsta bridge was funded by Viacon. Thanks also go to Mr. Stefan Trillkott and Mr. Claes Kullberg for performing the experimental tests.

\section{References}

1. Shift2Rail Masterplan 2014.

2. European Commission, Roadmap to a Single European Transport Area, COM(2011) 144 final.

3. J. Bién, L. Elfgren, J. Olofsson, SusB. D9.3 (2007).

4. T. Arvidsson, TRITA-BKN Bulletin 122, Licentiate Thesis (2014).

5. ORE, D23/RP 17/E (1971).

6. Cantero, D., LLB-KTH-REP-1.4 (2015).

7. ERRI, D214/RP8 (1999).

8. Guo, W., Xia, H., Karoumi, R., Zhang, T., Li, X., Wind and Structures vol. 20. No. 2 (2015).

9. RTRI, Displacement Limits (2007).

10. ERRI, D214/RP9 (1999).

11. Johansson, C., Andersson, A., Wiberg, J., ÜlkerKaustell, M., Pacoste, C., Karoumi, R., TRITABKN/R-139-SE (2010).

12. ERRI, D214/RP6 (1999).

13. Johansson, C., Pacoste, C., Karoumi, R., Comp.\& Struct. 119 (2013).

14. Johansson, C., Arvidsson, T., Martino, D., Solat Yavari, M., Andersson, A., Pacoste, C., Karoumi, R., TRITA-BKN/R-141-SE (2012).

15. Johansson, C., Andersson, A., Pacoste, C., Karoumi, R. TRITA-BKN/R-145-SE (2013).

16. Gazetas, G., J. Geotech. Eng. 117(9) (1991).

17. Ülker-Kaustell, M., Karoumi, R., Pacoste, R., Eng.Struct 32(2010).

18. Zangeneh Kamali, A., KTH (2015).

19. CEN, EN 1991-2 (2003).

20. ERRI, D214/RP4 (1999).

21. ERRI, D214/RP2 (1999).

22. M. Baeßler, J. Bronsert, P. Cuéllar \& W. Rücker. Bridge Maintenance, Safety, Management and Life Extension (2014).

23. Ülker-Kasutell, M., Karoumi, R., J. Rail Transp. 1(4) (2013).

24. Gonzales, I., Ülker-Kaustell, M., Karoumi, R., Eng.Struct 57 (2013).
25. Ülker-Kaustell, M., Karoumi, R., Eng.Struct 33 (2011)

26. Johansson, C., Nualláin, N.Á.Ní, Pacoste, C., Andersson, A., Eng. Struct 58 (2014).

27. James, G., Karoumi, R., Kullberg, C., Trillkott, S., TRITA-BKN/R-92-SE (2005).

28. García, A. L., TRITA-BKN/EX-320-SE (2011).

29. Fröidh, O., KTH Railway Group 12-01 (2012).

30. Andersson, A., Sundquist, H., Karoumi, R., Rydzyna 23-24.04.2012 (2012).

31. Mellat, P., Andersson, A., Pettersson, L., Karoumi, R., Eng. Struct 69 (2014).

32. Andersson, A., Ülker-Kaustell, M., Borg, R., Dymén, O., Karoumi, R., EVACES'15 (2015).

33. Borg, R., Dymén, O., TRITA-BKN/EX-460-SE (2015).

34. Rocha, J.M., Henriques, A.A., Calçada, R., Eng. Struct 71 (2014). 